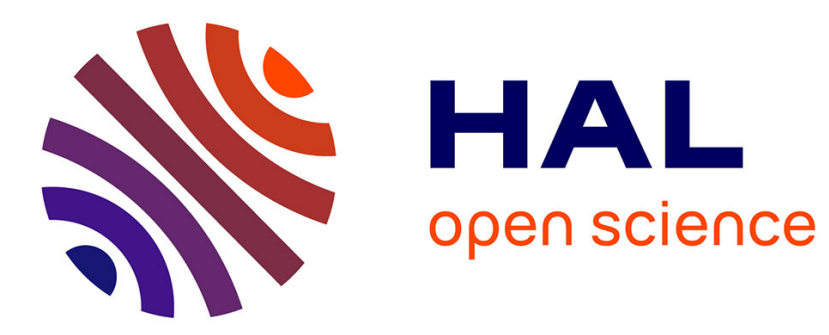

\title{
Supercapacitors aging diagnosis using least square algorithm
}

Amrane Oukaour, Mathieu Pouliquen, Boubekeur Tala-Ighil, Hamid Gualous, Eric Pigeon, Olivier Gehan, Bertrand Boudart

\section{To cite this version:}

Amrane Oukaour, Mathieu Pouliquen, Boubekeur Tala-Ighil, Hamid Gualous, Eric Pigeon, et al.. Supercapacitors aging diagnosis using least square algorithm. Microelectronics Reliability, 2013, European Symposium on Reliability of Electron Devices, Failure Physics and Analysis, 53 (9-11), pp.1638-1642. 10.1016/j.microrel.2013.07.032 . hal-00965762

\section{HAL Id: hal-00965762 https://hal.science/hal-00965762}

Submitted on 25 Mar 2014

HAL is a multi-disciplinary open access archive for the deposit and dissemination of scientific research documents, whether they are published or not. The documents may come from teaching and research institutions in France or abroad, or from public or private research centers.
L'archive ouverte pluridisciplinaire HAL, est destinée au dépôt et à la diffusion de documents scientifiques de niveau recherche, publiés ou non, émanant des établissements d'enseignement et de recherche français ou étrangers, des laboratoires publics ou privés. 


\section{A R T I C L E I N F O}

\section{Article history:}

Received 17 May 2013

Accepted 9 July 2013

Available online $\mathrm{xxxx}$

\begin{abstract}
A B S T R A C T
Supercapacitor aging is mainly related to thermal and voltage constraints. This aging causes degradation Q3 18 in the supercapacitor performances which can lead to the failure of this component. To avoid this failure, it is necessary to determine the supercapacitor state of health. The aim of this study is the supercapacitor diagnosis. In this paper, aging tests of supercapacitor subjected to calendar aging constraints are presented. The supercapacitor is aged at constant temperature and constant bias voltage. During the aging process, the variations of the supercapacitor equivalent series resistance (ESR) and equivalent capacitance $(C)$ are measured and analyzed. For diagnosis, a least square algorithm is used. This algorithm is used for ESR and $C$ identification during the supercapacitor operation. For vehicle applications, the supercapacitor is considered as aged when the capacitance loss is in order of $20 \%$ of its initial value, or if the value of the equivalent series resistance increases by a factor of 2 .
\end{abstract}

(c) 2013 Published by Elsevier Ltd.

\section{Introduction}

Supercapacitors are used to assist the power of a battery or a fuel cell in numerous applications. They can be used to store energy and to provide peak power demands, in power electronics systems, in parallel with batteries or fuel cells. For example in a hybrid vehicle the supercapacitor can provide peak power requirement in transient state and to store the regenerative energy [1-6]. In several applications, supercapacitors are charged and discharged at high current. This effect causes heating in the supercapacitor and accelerates their aging. It is known that the supercapacitor aging is mainly related to thermal and voltage constraints applied to the device [7-11].

In several applications, the improvement of supercapacitors reliability is fundamental. The follow-up of the supercapacitor state of health and the detection of an aging state enable to avoid some breakdowns. The knowledge of the system's state permits to avoid operational failures and thus to intervene at the convenient moment before a breakdown occurs. Several diagnosis methods exist $[14,15]$ which permit from adequate measures, to analyze the aging state of this component.

Finally, our work deals with the diagnostic of the supercapacitor aging state based on the estimation of both the series resistance and the capacity. This algorithm uses the measurement data which are the voltage and the charge/discharge current of the component. This is the first study presented in the literature that deals with the

\footnotetext{
* Corresponding author. Tel.: +33 (02) 330146 11; fax: +33 (02) 33014599

E-mail address: amrane.oukaour@unicaen.fr (A. Oukaour).
}

diagnosis of the failures due to the aging phenomenon by an optimization using a least square algorithm.

This method is based on the estimation of the electrical equivalent circuit parameters of the component. Identification test at the beginning and at different phases of the supercapacitor calendar aging is realized. This method is used to identify the values of the equivalent series resistance and the capacitance at different stages of the operation process. The comparison is performed between initial and the following states, respectively. Supercapacitors offer a high number of charge and discharge cycles. The device's lifetime is very long. In order to carry out this study during a reasonable time, an accelerated supercapacitor calendar aging process is realized.

\section{Calendar aging protocol}

In order to perform the aging test, a dedicated test bench was developed (Fig. 1).

A supercapacitor is placed inside a climatic chamber at $60^{\circ} \mathrm{C}$ and polarized at $3 \mathrm{~V}$ voltage during the aging process. Taking into account the boiling point temperature of the electrolyte which is in order of $81.6{ }^{\circ} \mathrm{C}$ (at atmospheric pressure), the temperature value is selected in order to make it possible to observe the aging rather quickly. Supercapacitor aging is carried out following several phases. The durations of the different phases are given in Table 1 .

Initially and after each phase of the aging, the supercapacitor is characterized at room temperature. This characterization consists of charging and discharging the supercapacitor by using the test 


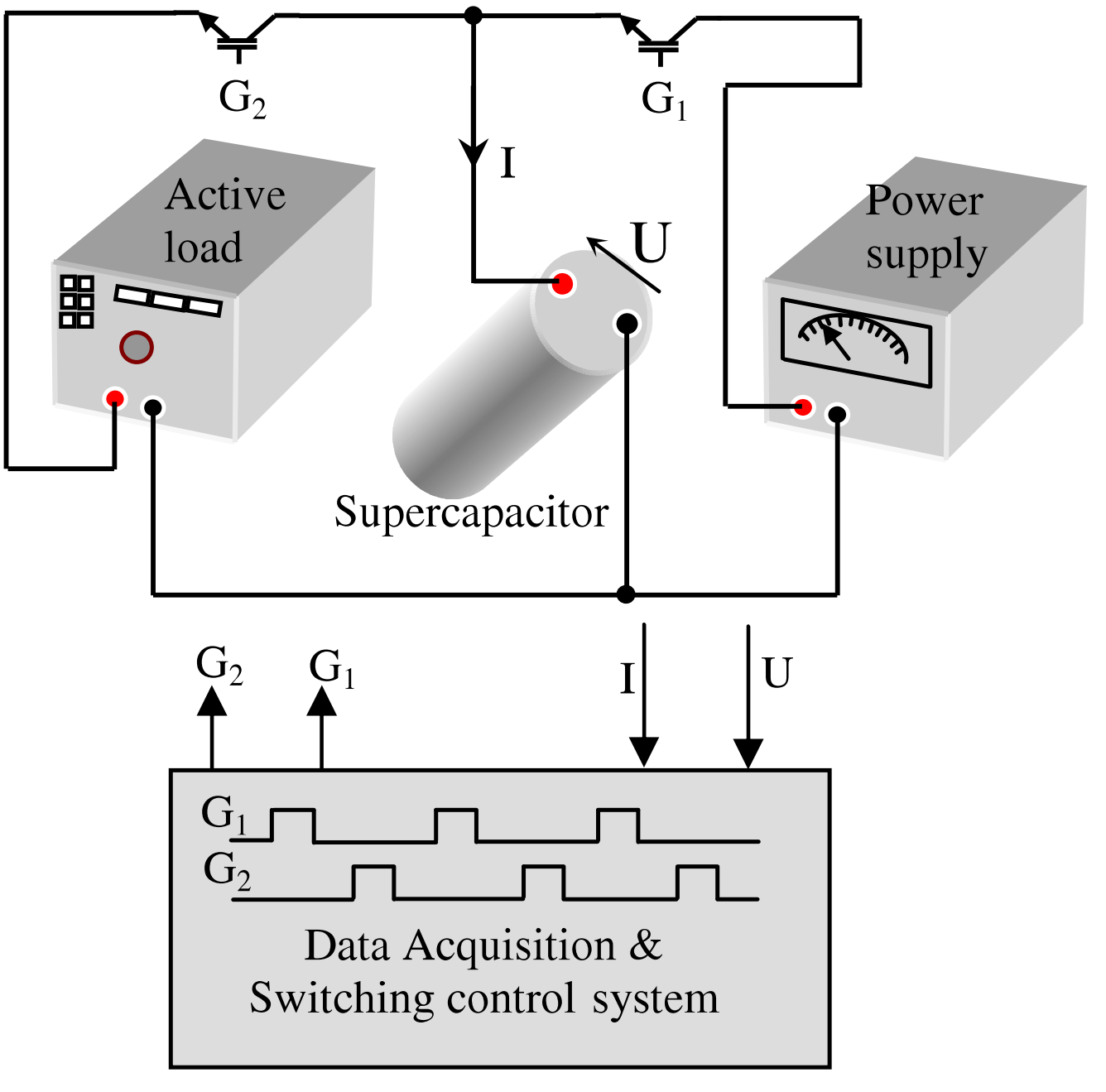

Fig. 1. Overview of the test bench.

Table 1

Supercapacitor ESR and $C$ variations according to the calendar aging time.

\begin{tabular}{lcrcc}
\hline Aging time $(\mathrm{h})$ & 0 & 327 & 536 & 774 \\
$\operatorname{ESR}(\mathrm{m} \Omega)$ & 2.4 & 4 & 5.2 & 6.2 \\
$C(\mathrm{~F})$ & 380 & 313 & 283 & 238 \\
ESR variation $(\%)$ & 0 & 66 & 116 & 158 \\
$C$ variation $(\%)$ & 0 & -17 & -25 & -37 \\
\hline
\end{tabular}

bench presented in Fig. 1, at constant current (10 A) as shown in Fig. 2.

The parameters of the device such as the equivalent series resistance (ESR) and the equivalent capacitance $\hat{C}$ are measured before and after each aging phase.

The test bench is monitored using an acquisition board with an implemented MATLAB program. These experimental results are used to identify the evolution of the ESR and the capacitance. The calculation of the equivalent series resistance ESR and the equivalent capacitance $C$ is based on the following expressions:

$\mathrm{ESR}=\frac{\Delta V}{I}$ and $C=I / \frac{\Delta V_{0}}{\Delta t_{0}}$

The different parameters used in the above expressions are presented in Fig. 2.

The voltage drop $\Delta V$ is measured between the current interruption and the intersection with the linear regression of the self-discharge curve, as described in the standard IEC62391.

As described previously, the aging behavior is determined by the increase of the ESR and by the loss of the equivalent capaci-

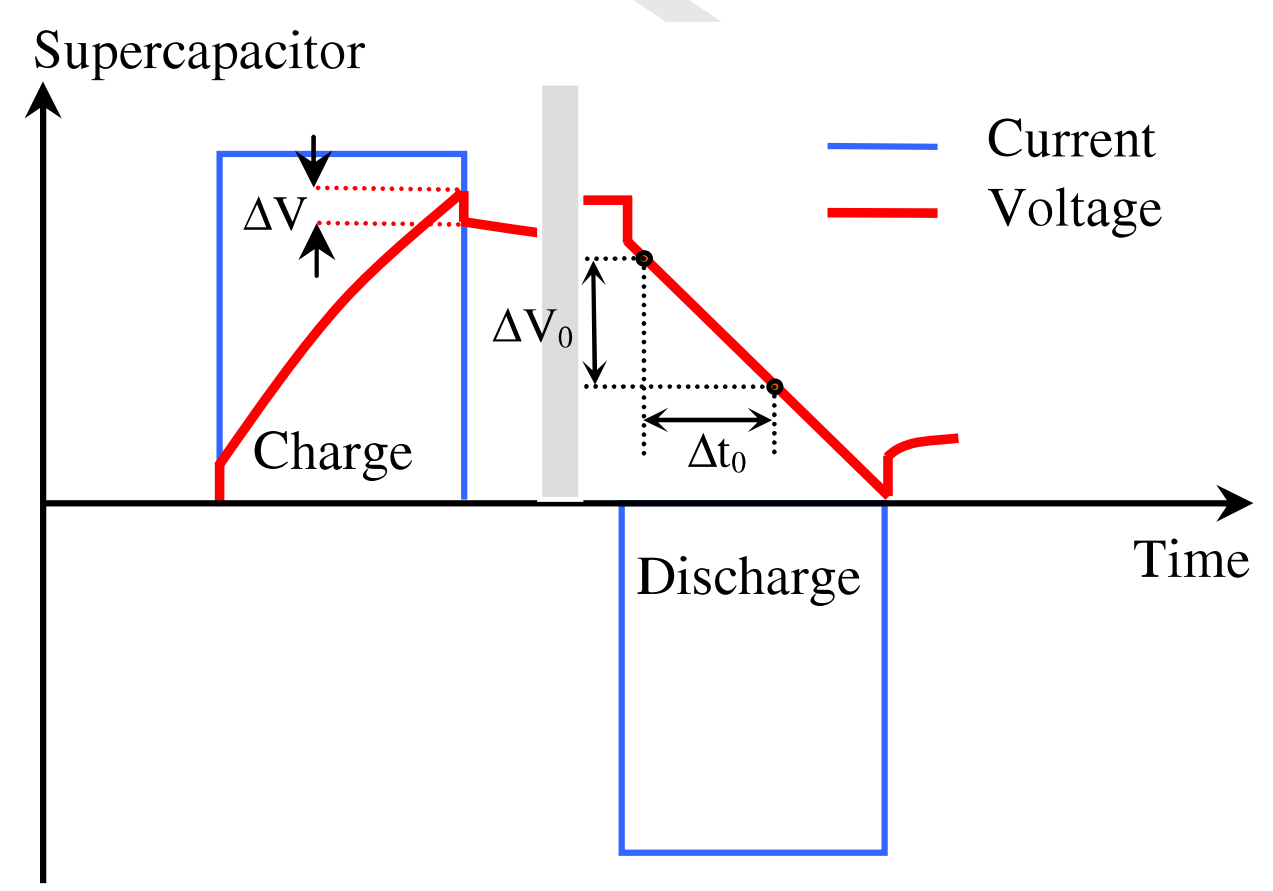

Fig. 2. Identification method of $C_{0}$ and ESR. tance. For this reason, these parameters were measured before and after each aging phase. Figs. 3 and 4 present the supercapacitor voltage variation with time during charge and discharge at constant current $(10 \mathrm{~A})$ and for various aging time. It can be seen that the time of charge and discharge decreases with the duration of aging. This phenomenon is related to the reduction in the supercapacitor capacitance with aging process.

These results show also that the drop of the voltage at the end of the supercapacitor charge (current interruption) increases with the duration of calendar aging. This means that the equivalent series resistance ESR increases. This phenomenon is accelerated by increasing the temperature and by imposing a high bias voltage. We synthesized these results in Table 1.

It can be seen that the ESR increases and $C$ decreases with aging time. For example, when the supercapacitor is polarized at $3 \mathrm{~V}$ and the temperature is fixed at $60^{\circ} \mathrm{C}$ and after $536 \mathrm{~h}$ of calendar aging, the ESR increase is in order of $116 \%$ and the çapacitance decrease is in order of $25 \%$.

For vehicle applications, the supercapacitor is considered as aged when the capacitance loss is in order of $20 \%$ of its initial value, or if the value of the equivalent series resistance increases by a factor of 2. Thus, it is very important to consider these two parameters as some good indicators of aging in order to perform a diagnosis method for the supervision of the device state during its operation. The degradation of ESR and $C$ will have a considerable impact on the ability of the energy storage of the supercapacitor.

The energy depends particularly on the value of the capacitance $C$ and the performance of the supercapacitor depends on the quantity of energy losses and thus on the evolution of the ESR.

\section{Identification methodology}

\subsection{Model description}

Among the equivalent electrical models proposed in the literature, a commonly used model is a model including a resistance and a series of $\mathrm{n} \mathrm{RC}$ parallel branches [12]. Here, we have focused on the simple RC series circuit represented in Fig. 5. This model is not suitable for an accurate modeling of the supercapacitor dynamic behavior in a wide frequency range, however this model will be considered reliable enough given the current profile used and the frequency range of this current (the sampling period will be chosen sufficiently small). Also note that here we are interested in a degradation of parameters over time and not in an accurate assessment of their values.

The input/output behavior of the model is given by:

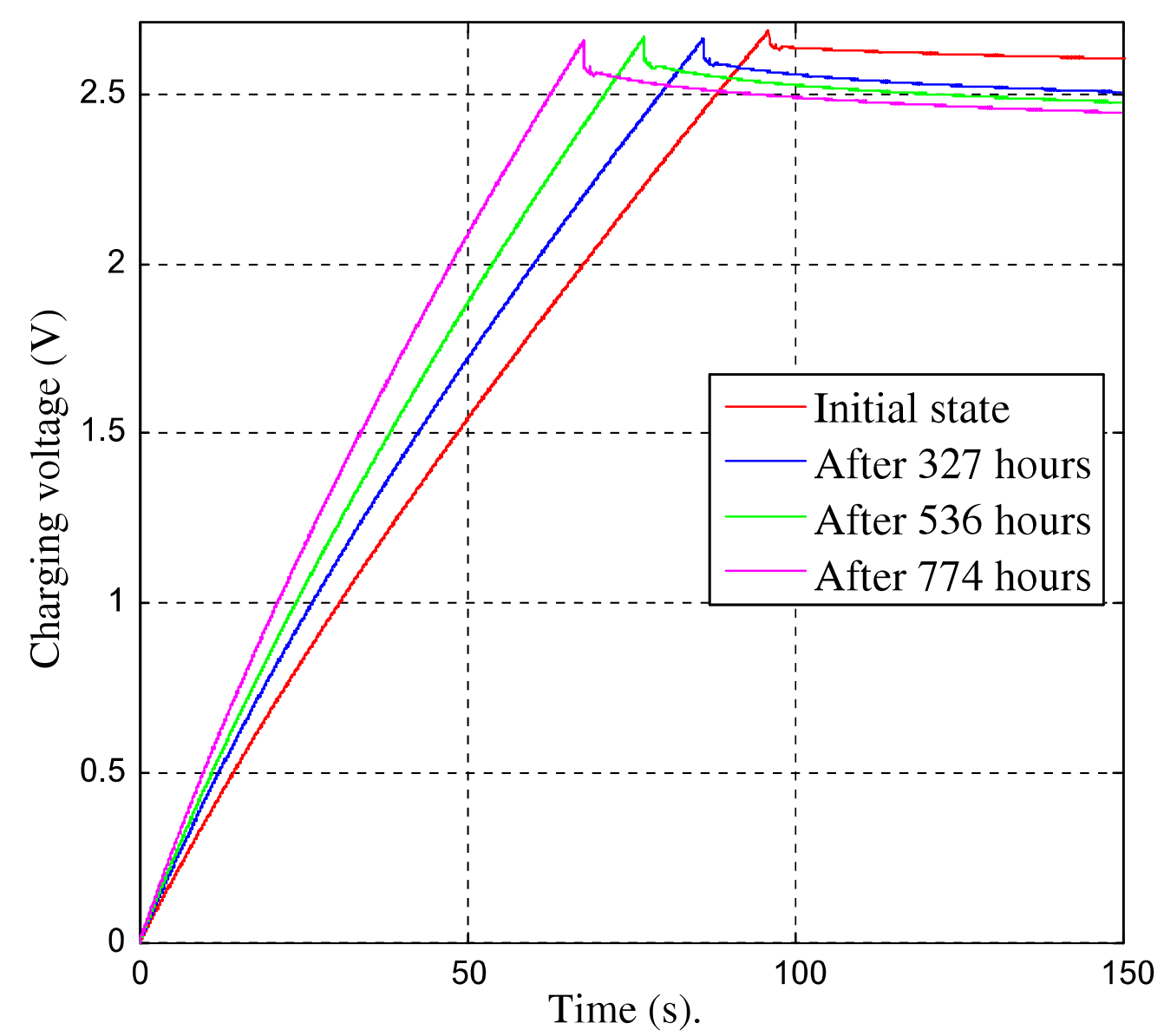

Fig. 3. Supercapacitor charge at $10 \mathrm{~A}$ constant current for different aging times. 


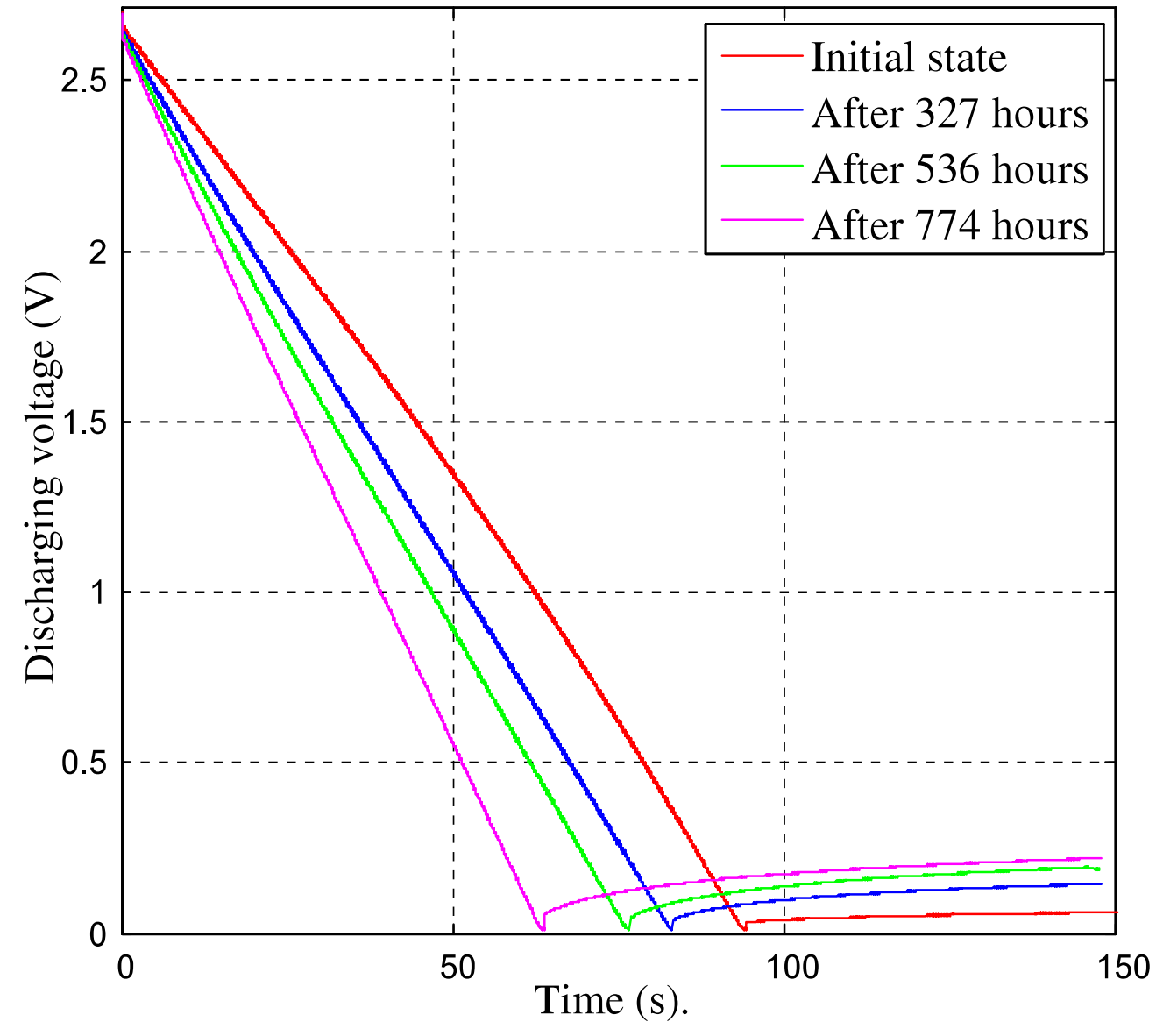

Fig. 4. Supercapacitor discharge at $10 \mathrm{~A}$ constant current for different aging times.

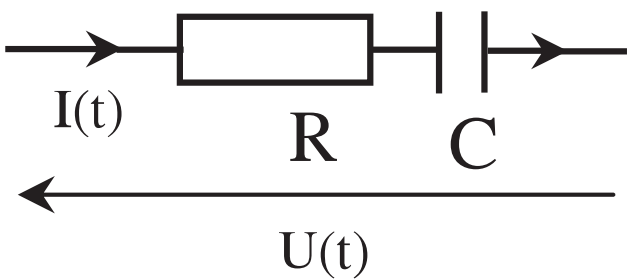

Fig. 5. Simple RC series circuit.

$U(t)=R \cdot I(t)+\frac{1}{C} \cdot \int_{0}^{t} I(\tau) \cdot d \tau$

where $R$ is the equivalent series resistance (ESR) and $C$ is the capacitance.

$U(t)$ and $I(t)$ are the voltage and the current, respectively. The estimation of the supercapacitor parameters is performed from the measurement of the current and the voltage during a time interval as described in Fig. 6. It has been established in the literature that the capacitance value depends on the voltage [12]: $C=C_{0}+k \cdot U$. In order to consider the capacitance as constant, the observation time will be assumed short.

To enable a persistent excitation of the component, a current profile has been chosen as follows:

$I(t)=I+i(t)$, with $i(t)$ such that:

$i(t)= \begin{cases}+\delta & \text { if }(2 \cdot k-1) \cdot T_{s} \leqslant t \leqslant 2 \cdot k \cdot T_{s} \\ -\delta & \text { if } 2 \cdot k \cdot T_{s} \leqslant t \leqslant(2 \cdot k+1) \cdot T_{s}\end{cases}$

$T_{s}$ is the sampling period, $I$ is a constant term and $\delta$ is the amplitude of the excitation signal (see Fig. 7).

This excitation is needed to allow a high signal to noise ratio, however it should not be too large so as not to disturb the component. The used current profile is illustrated in Fig. 7.

Signals $U(t)$ and $I(t)$ are sampled at the period $T_{s}$. On a short time interval and from the current profile described above, it is possible to rewrite the model (1) as follows:

$U(t)=R \cdot I(t)+\frac{1}{C} I_{f}(t)+C^{t e}$

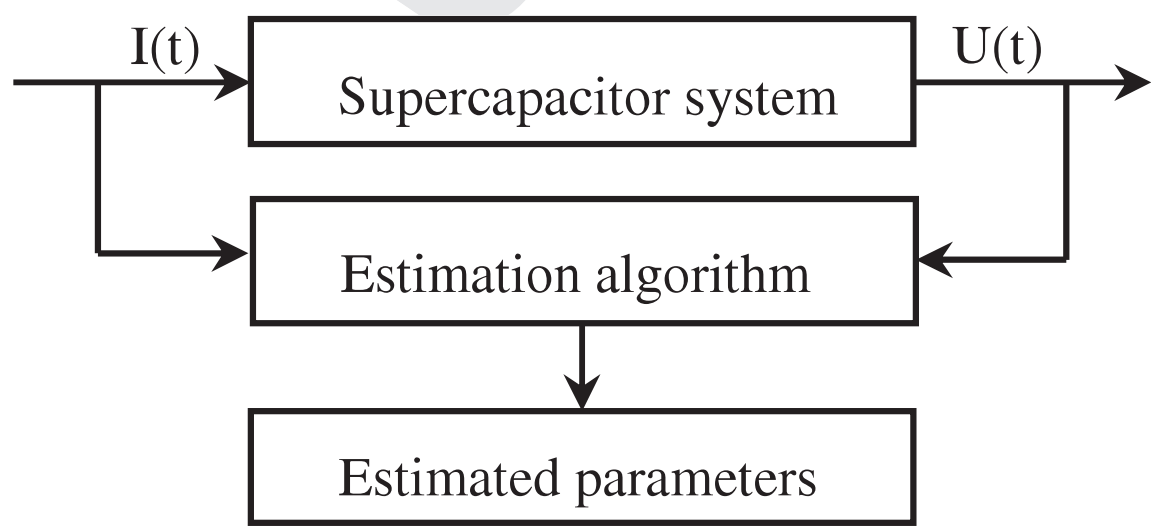

Fig. 6. Parameters estimation.

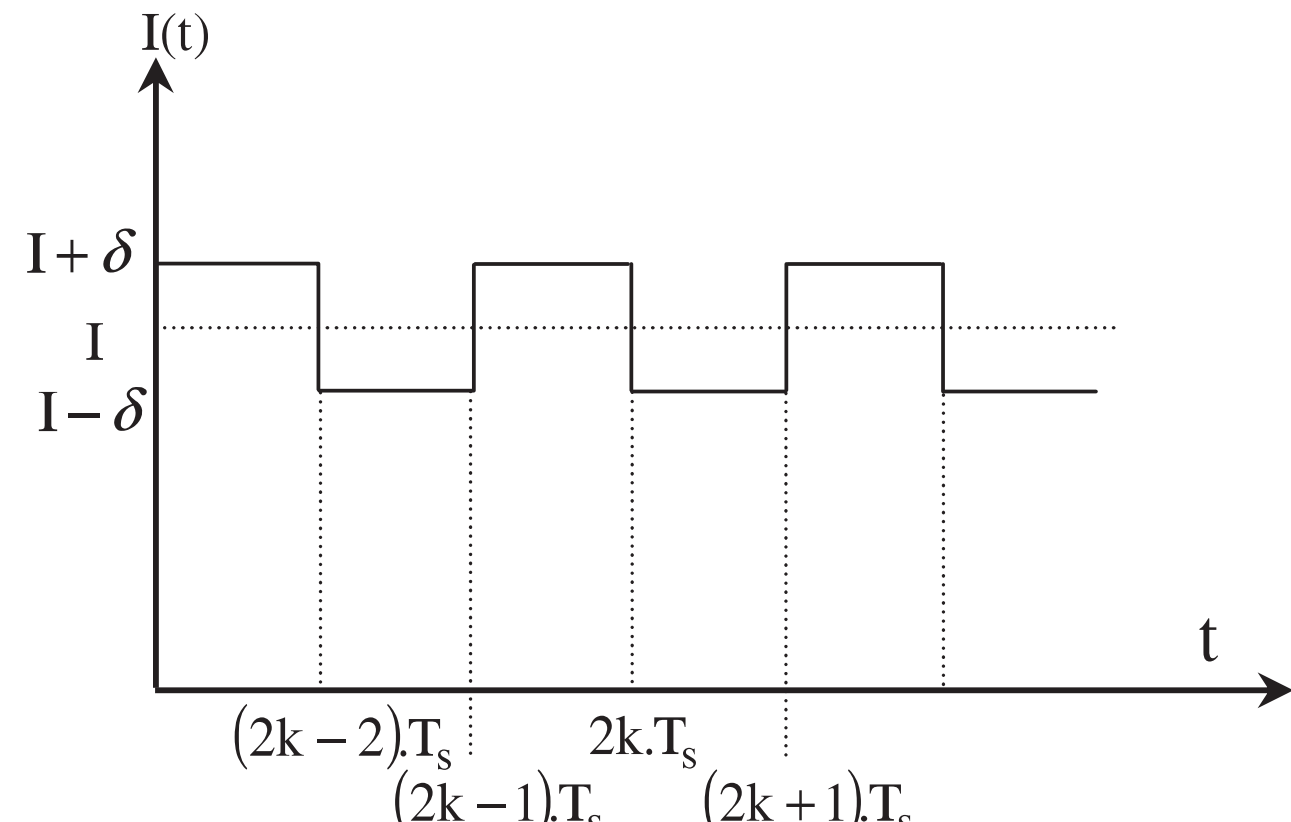

Fig. 7. Excitation signal.

with $t=k \cdot T_{s}, I_{f}(t)=\int_{0}^{t} I(\tau) \cdot d \tau, I_{f}(t=0)=0$ and $C^{\text {te }}$ is a constant term.

The estimation algorithm presented in the next subsection is based on this discrete time model.

\subsection{Estimation algorithm}

Estimation of the parameters treated in this paragraph is presented under the following formulation. The goal is to calculate the values of ESR and $C$ by having measurements values of input $I(t)$ and output $U(t)$ on the time interval $\left[T_{s} \cdots N \cdot T_{s}\right]$. To achieve this goal, Eq. (2) can be rewritten in a regression form $U(t)=\Phi(t)^{T} \theta$, with:

$\theta=\left[\begin{array}{l}R \\ 1 / C \\ C^{t e}\end{array}\right]$ and $\Phi(t)=\left[\begin{array}{l}I(t) \\ I_{f}(t) \\ 1\end{array}\right]$

This formulation allows us to use identification methods such as those describe in [13]. In this study, the well-known least squares method has been chosen, this method makes the solution simpler and more intuitive in the authors view. This method consists of adjusting the parameters so as to minimize the sum $\sum_{k=1}^{N}\left[U\left(k \cdot T_{s}\right)-\Phi\left(k \cdot T_{s}\right)^{T} \cdot \theta\right]^{2}$. The optimum can be analytically computed, which gives, provided the indicated inverse exists, $\hat{\theta}=\left(\Phi \cdot \Phi^{T}\right)^{-1} \cdot \Phi \cdot U$.

$\mathrm{Z}$ With $\Phi=\left[\begin{array}{llll}\Phi\left(T_{S}\right) & \Phi\left(2 \cdot T_{s}\right) & \cdots & \Phi\left(N \cdot T_{s}\right)\end{array}\right] \quad$ and $U=\left[\begin{array}{l}U\left(T_{s}\right) \\ U\left(2 \cdot T_{s}\right) \\ \vdots \\ U\left(N \cdot T_{s}\right)\end{array}\right]$

\subsection{Experimental study}

The parameters of the supercapacitor have been estimated over $500 \mathrm{~ms}$. This experimental condition induces low level voltage variation so that the voltage can be considered constant. Consequently, the capacitance $C$ can be assumed to be a constant, a necessary condition for the application of the estimation procedure. Because of measurement noise, a shorter measurement time may degrade the quality of the estimation. The sampling period has been fixed at $T_{s}=10 \mathrm{~ms}$. On that frequency range, the simple $\mathrm{RC}$ series circuit can approximate the behavior of the supercapacitor. A more accurate modeling would be obtained with a higher sampling period, however the estimation would require a longer measurement time and therefore a significant change in voltage.

The amplitude of the excitation is $\delta=0.4 \mathrm{~A}$. Several steps of current $I$ have been successively applied.

We validated our result, in this section, by estimating the indicators of aging at the beginning ( $0 \mathrm{~h}$ aging), the middle (after $327 \mathrm{~h}$ aging) and the end of the process (after $774 \mathrm{~h}$ aging). 
At each phase of calendar aging and by using the least squares algorithm, the identification of the equivalent series resistance is carried out.

Fig. 8 shows the evolution of these estimates according to the supercapacitor voltage. On these curves, each point corresponds to an estimate on $500 \mathrm{~ms}$.

We note that the increase of ESR according to the aging time is confirmed.

The comparison between the ESR values obtained from the experimental charging curves with that implemented from the identification least squares algorithm is made.

For this purpose, we have calculated at each stage of calendar aging the average value of the estimated ESR.

The ESR evolution obtained from experimental results (standard IEC62391) and the estimated one are plotted in Fig. 9.

The difference between the two methods for determining the ESR is due to the fact that the method using the least squares algorithm is based on a simple model.

This model describes only a part of the behavior of the component (the gap will not be filled with a longer measurements interval or a higher SNR). However, the trend on these two curves is in

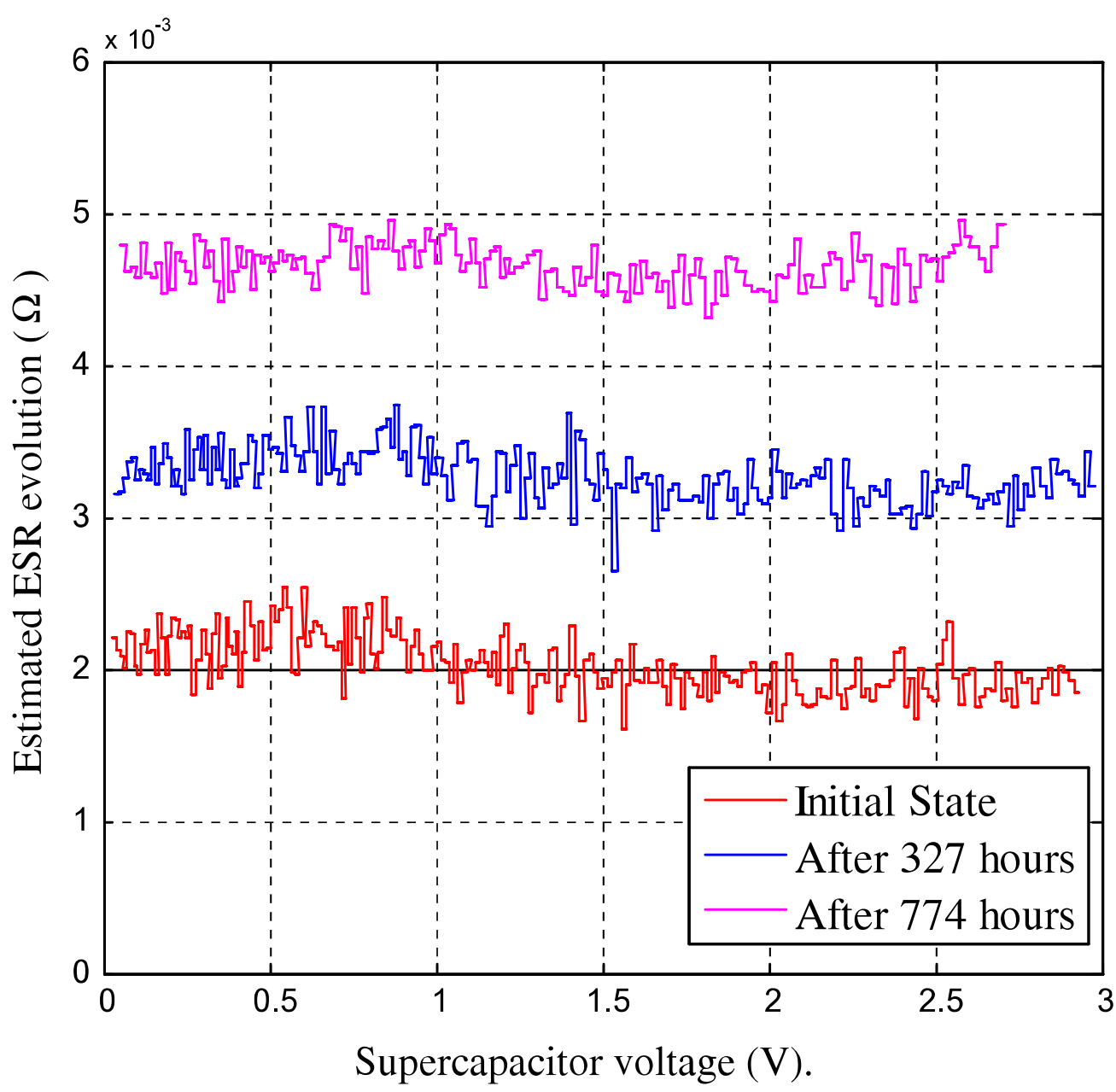

Fig. 8. Estimated ESR evolution.

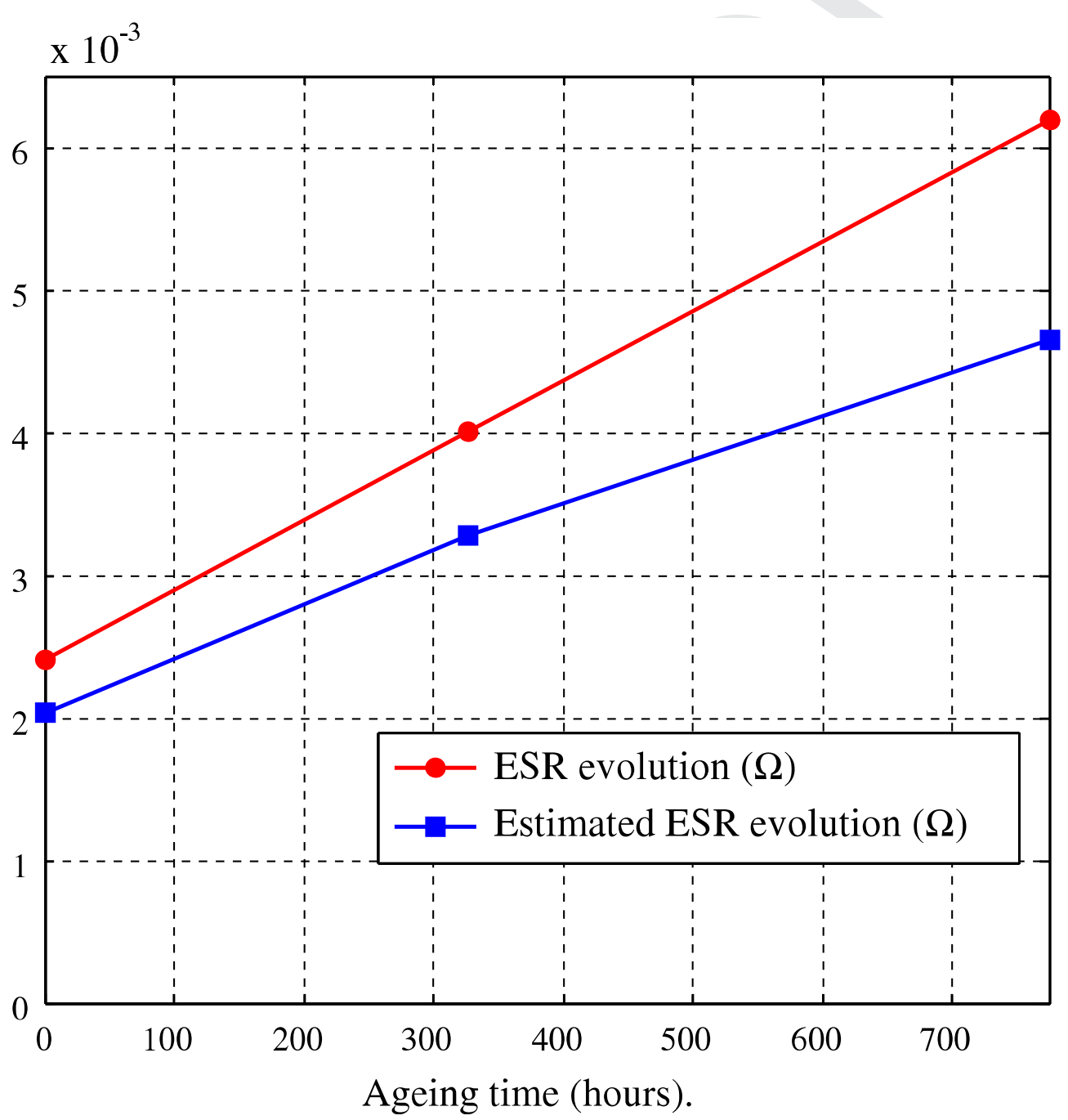

Fig. 9. Evolution of measured and estimated ESR according to the aging time.

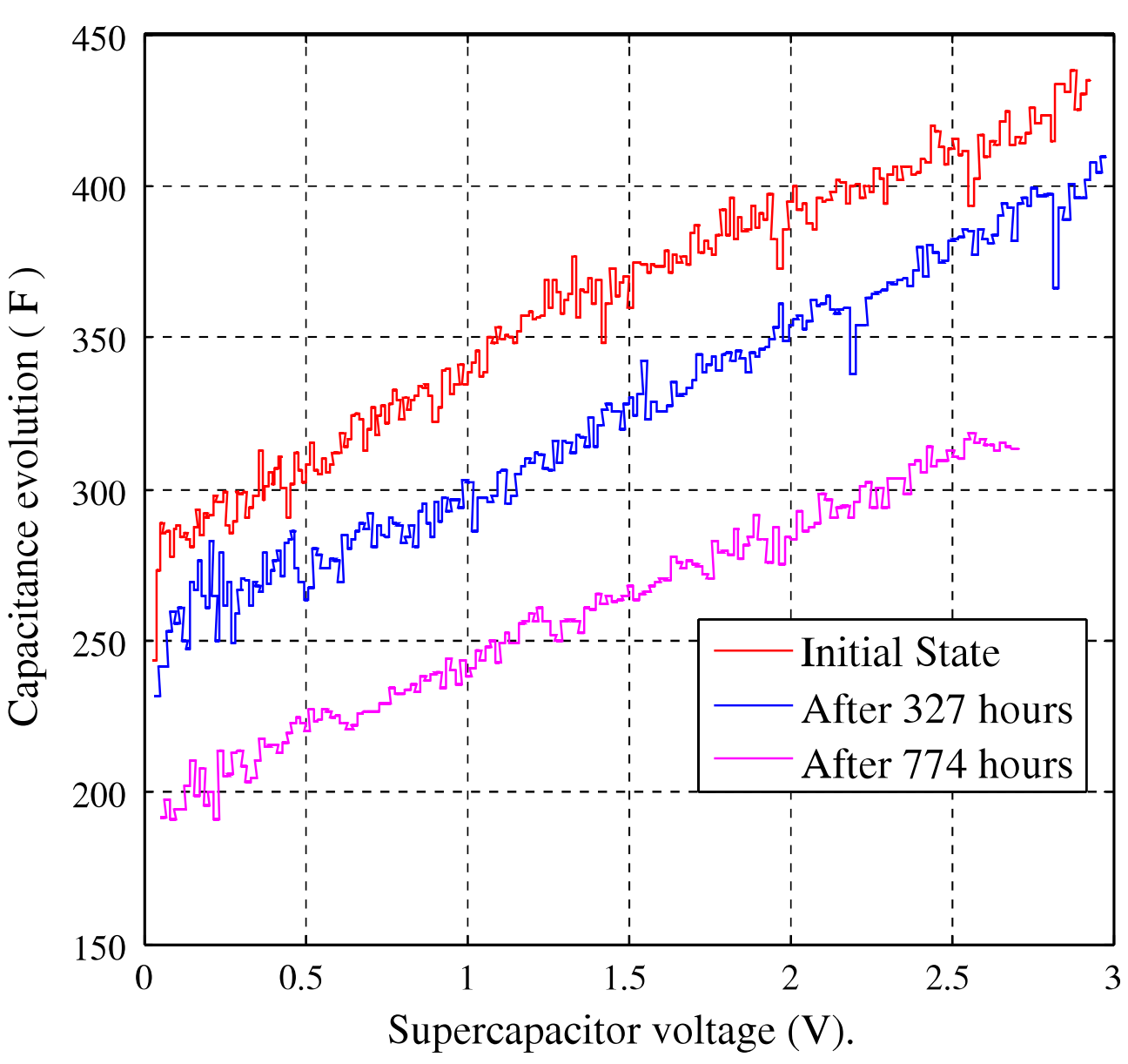

Fig. 10. Estimated $C$ versus supercapacitor voltage.

good agreement and consequently the observation of the estimated ESR is enough to assess the performance decay with aging.

A second indicator of supercapacitor aging is represented by the equivalent capacitance $C$ on which we paid a special attention to examine it. Thus, the value of the supercapacitor capacitance at the initial state and at each stage of its aging is identified. The estimated value by the least squares algorithm depends on the supercapacitor voltage value. The obtained results are presented in Fig. 10, which gives the variation of the estimated capacitance according to the voltage. It can be noticed that the average value of $C$ varies linearly with the supercapacitor voltage.

\section{Conclusion}

This paper presents calendar aging of activated carbon and organic electrolyte supercapacitor. The aging of supercapacitors is related to the voltage and to the temperature. To investigate this effect, a test bench of accelerated supercapacitor calendar aging was conducted. Experimental tests are performed at constant temperature $\left(60^{\circ} \mathrm{C}\right)$ while the supercapacitors are polarized at $3.0 \mathrm{~V}$. In order to quantify the supercapacitors aging, the equivalent series resistance and the capacitance are measured using the DC characterization method. The experimental results have shown that the supercapacitor equivalent series resistance increases with calendar aging and the capacitance decreases. These two indicators are used for the supercapacitors aging diagnosis.

A method based on a least square algorithm is used to estimate the supercapacitor parameters over the aging time. The obtained results show that the method used for ES $\hat{R}$ and $C$ estimation is satisfactory and can be used easily for supercapacitor diagnosis. The identification process can be implemented in a microcontroller or a DSP.

\section{References}

[1] Thounthong P, Chunkag V, Sethakul P, Davat B, Hinaje M. Comparative study of fuel-cell vehicle hybridization with battery or supercapacitor storage device. IEEE Trans Vehicular Technol 2009:58(8):3892-904.

[2] Hanmin L, Zhixin W, Jie C, Maly D. Improvement on the cold cranking capacity of commercial vehicle by using supercapacitor and lead-acid battery hybrid. IEEE Trans Vehicular Technol 2009;58(3):1097-105.

[3] Camara M, Gualous H, Gustin F, Berthon A. Design and new control of DC/DC converters to share energy between supercapacitors and batteries in hybrid model of supercapacitors stack. IEEE Trans Ind Electron 2012;59:987-97.

[5] Gualous H, Louahlia-Gualous H, Gallay R. Supercapacitors characterization and thermal modelling with reversible and irreversible heat effect. IEEE Trans Power Electron 2011;26(11):3402-9. vehicle. IEEE Trans Vehicular Technol 2008;57(5):2721-35.

[4] Hijazi A, Kraczanik P, Bideaux E, Venet P, Clerc G, DiLoreto M. Thermal network 
[6] Camara MB, Gualous H, Gustin F, Berthon A, Dakyo B. DC/DC converter design for supercapacitor and battery power management in hybrid vehicle applications-polynomial control strategy. IEEE Trans Ind Electron 2010;57(2):587-97.

[7] Diab Y, Venet V, Gualous H, Rojat G. Self-discharge characterization and modelling of supercapacitors used for power electronics applications. IEEE Trans Power Electron 2009;24(2):510-7.

[8] Hammar A, Venet P, Lallemand R, Coquery G, Rojat G. Study of accelerated aging of supercapaitors for transport applications. IEEE Trans Ind Electron 2010;57:3972-9.

[9] El Brouji E-H, Briat O, Vinassa J-M, Bertrand N, Woirgard E. Impact of calendar life and cycling aging on supercapacitor performance. IEEE Trans Vehicular Technol 2009;58(8):3917-29.

[10] Rizoug N, Bartholomeus P, Le moigne P. Modeling and characterizing supercapacitors using an online method. IEEE Trans Ind Electron 2010;57:3980-90.
[11] Buller S, Karden E, Kok D, De Donker RW. Modelling the dynamic behaviour of supercapacitors using impedance spectroscopy. In: Proc IEEE ind appl conf (IAS), Chicago, vol. 4, 2001. p. 2500-2504.

[12] Rafik F, Gualous H, Gallay R, Crausaz A, Berthon A. Frequency, thermal and voltage supercapacitor characterization and modeling. J Power Sources 2007;165(2):928-34.

[13] Ljung L. System identification: theory for the user. Prentice Hall; 1999.

[14] Tongzhen W, Sibo W, Xuhua G. Deterioration diagnosis of ultracapacitor for power electronics applications. In: Sustainable Power Generation and Supply, 2009. SUPERGEN ‘09. International Conference, pp. 1-6.

[15] Tang Z, Fang Y, Peng Q A LabVIEW-based fault diagnosis system for lithiumion battery. In: Power and energy engineering conference (APPEEC), 2011 Asia-Pacific; 2011, p. 1-4. 